\title{
Young Malaysian Consumers' Attitude and Intention to Imitate Korean Celebrity Endorsements
}

\author{
Wan Roazha Wan Mat \\ Faculty of Business, Economics and Accountancy, Universiti Malaysia Sabah, Kota Kinabalu, \\ Malaysia \\ Hyung Jun Kim \\ College of Economics and Management, Chungnam National University, South Korea
}

\begin{abstract}
Ahmad Azaini Abdul Manaf
Faculty of Applied and Creative Arts, Universiti Malaysia Sarawak, Kota Samarahan, Malaysia

Grace Phang Ing

Faculty of Business, Economics and Accountancy, Universiti Malaysia Sabah, Kota Kinabalu, Malaysia

Azaze-Azizi Abdul Adis

Faculty of Business, Economics and Accountancy, Universiti Malaysia Sabah, Kota Kinabalu, Malaysia
\end{abstract}

\begin{abstract}
This study addressed the issue of young Malaysian consumers' intention to imitate Korean celebrities' endorsement in advertisements. The researchers specifically focused on the impact of Korean celebrity characteristics and the consumer's individual characteristics on the latter's attitude towards imitating celebrity endorsements and the consumer's intention to imitate. 602 young Malaysian consumers in the Klang Valley participated in this study. The results pointed to celebrity characteristics namely attractiveness and trustworthiness as directly and indirectly significant, whilst credibility and expertise were directly and indirectly not significant predictors on consumer attitude toward imitating celebrity endorsements. In addition, individual characteristics namely self-satisfaction and expression of power were directly and indirectly significant predictors on consumer attitude towards imitating celebrity endorsements. There was also a significant effect on attitude towards imitating celebrity endorsements on intention to imitate. Suggestions for future research are discussed at the end of this paper.
\end{abstract}

Keywords: Korean Wave, Celebrity Characteristics, Individual Characteristics, Attitude toward Imitating Celebrity Endorsement, Intention to Imitate 


\section{Introduction}

Korean Wave refers to a cultural phenomenon in which people all over the world are willing to adopt Korean popular culture (Jung, 2006). The four main categories of Korean Wave are Korean Drama (K-drama), Korean Pop Music (K-pop music), Korean Culture (K-culture) and Korean Style (K-style) (Rae, 2015). Korean Wave or Hallyu started with K-drama exports in the late 1990s. The popularity of Korean TV dramas and Korean pop music have made the Korean Wave more successful and attractive with its influence spreading to a large audience across Asian countries (Bae, 2007). According to Ariffin, Abu Bakar \& Yusof (2018), Hsu (2012), Jin \& Jeong (2010), Rhee \& Lee (2010), and Vu \& Lee (2013), the popularity of K-drama has sparked interest among researchers to study their effects on audiences. This is also supported by Ariffin, Othman \& Abdullah (2013) who report that among Malaysian teenagers, Hallyu is popular and has been successfully absorbed into the life of Malaysian teenagers in particular and Asian teenagers in general.

This is perhaps one of the reasons why marketers prefer celebrities in product or brand endorsements since they are attractive (Erdogan, 1999). Celebrities also frequently influence consumers' attitude (Ranjbarian, Shekarchizade, \& Momeni, 2010; Ariffin, Abu Bakar \& Yusof, 2018). Ranjbarian et al. (2010) posit that celebrity endorsement makes for better advertising by creating positive impacts on consumers' attitude towards celebrity endorsement. Based on a study by Khan and Lodhi (2016), celebrity endorsement attracts target consumers due to its persuasiveness. The appearance of celebrities on the TV screen whether as an endorsement or TV personality is a vicarious role model that could greatly influence their audience and admirers' personal behaviour (Makgosa, 2010; Bush \& Martin, 2000) especially teenagers who would observe, copy or reproduce the behaviour of others (Bush \& Bush, 2004) as part of their learning process and the formation of their own personal identity. Good personal characteristics of the celebrity endorsement would be a positive drive of imitated behaviour (Awasthi \& Choraria, 2015).

Previous researchers examined various issues related to celebrity endorsement (Roy \& Hyderabad, 2012) in the field of psychology, sociology and consumer behaviour (Ariffin, Abu Bakar \& Yusof, 2018; McCracken, 1989; Cronley, Kardes, Goddard, \& Houghton, 1999; Kirmani \& Shiv, 1998; Mowen, 1980; Marshall, 2008; Tantiseneepong, 2012). Their studies however were mainly focused on the effectiveness of celebrity endorsement in predicting consumer behavioural intentions (Wei \& Li, 2013), attitude towards product (Silvera \& Austad, 2003), determining the effectiveness of celebrity endorsement (Ibok, 2013), celebrity influence on audience and consumer habits (Zipporah \& Mberia, 2014), and buying behaviour (Nyarko, Asimah, Agbemava, \& Tsetse, 2015). In different cultures however (Rashid et al., 2002), there have been limited studies which were focused on consumer intention to imitate their favorite celebrity. This study therefore intended to examine the influence of Korean celebrities on consumer attitude and intention to imitate in the context of celebrity endorsement. 
Past studies also examined issues related to celebrity endorsement such as the effectiveness of celebrity endorsement (Md. Said \& Wan Napi, 2015; Awasthi \& Choraria, 2015; Zafar \& Rafique, 2015). The variables that were commonly used were attractiveness (Renton, 2009; Emma \& Matilde, 2017; Awasthi \& Choraria, 2015; Gauns, Pillai, Kamat, Chen \& Chang, 2018; Aziz, Omar \& Ariffin, 2019), credibility (Gauns, Pillai, Kamat, Chen \& Chang, 2018; Malik \& Qureshi, 2016; Erdogan, Baker, \& Tagg, 2001; Renton, 2009), expertise (Gauns, Pillai, Kamat, Chen \& Chang, 2018; Malik \& Qureshi, 2016; Ohanian, 1990; Spry, Pappu, \& Cornwell, 2011), and trustworthiness (Gauns, Pillai, Kamat, Chen \& Chang, 2018; Malik \& Qureshi, 2016; Awasthi \& Choraria, 2015; Emma \& Matilde, 2017; Aziz, Omar \& Ariffin, 2019) using meaning transfer models (Ohanian, 1990; Silvera \& Austad, 2003; Kahle \& Homer, 1985). In addition, a number of variables were considered to measure the effectiveness of celebrity endorsement by looking into positive word-of-mouth (Bush, Martin, \& Bush 2004), celebrity-product congruence (Gauns, Pillai, Kamat, Chen \& Chang, 2018; Friedman \& Friedman, 1979; Kahle \& Homer, 1985; Kamins, 1990; Kamins \& Gupta, 1994; Till \& Busler, 2000; Tingchin, Hung, \& Minghua, 2007), and peer influence (Mangleburg \& Bristol, 1998), advertising belief and personal value (Ting \& de Run, 2015). However, very few studies attempted to combine together attractiveness, credibility, trustworthiness, expertise, expression of power and self-satisfaction on the attitude towards celebrity endorsement which in turn would contribute to comprehensive factors that influence consumer intention to imitate.

\section{Literature Review}

\section{Para-social Interaction Theory}

The term "para-social interaction" was coined by Horton \& Wohl (1956) to address the illusion of a face-to-face relationship between viewers and the performer. Para-social interaction has since evolved to be defined as the illusory face-to-face interaction that occurs when media viewers have to interact with their media figures. The viewers feel they are involved in the scene and start to interact with the character even though the two-way communication is impossible (Horton \& Wohl, 1956). Hence the term "parasocial" - the viewer only feels the illusory face-to-face interaction that occurs when media viewers make interaction with their media figures (Horton \& Wohl, 1956). Based on the definition of para-social interaction mentioned above, the viewer and performer are referred to as the consumer and celebrity endorser in the marketing context.

\section{Theory of Imitation}

The theory of imitation (Tarde, 1969; Baldwin, 1925) is an individual developmental process and applies to the growth of society. People are born with weaknesses and strengths in their physical appearance, personality and style; this influences them to spend hours making their appearance "fit in" with the norms of the group with whom they most fit while at the same time assuming their own unique style. They would spend hours in front of the mirror trying to achieve these goals (Gentry \& Campbell, 2002). The process of individual life could be implied in social life when the individual attempts to imitate something interesting and beneficial such as physical attractiveness 
and good style (Ellwood, 1901). Through imitation habits people gain confidence and become comfortable living in society (Bandura, 1977).

\section{Celebrity Characteristics}

\section{Attractiveness}

According to Erdogan (1999), attractiveness encompasses concepts such as intellectual skill, personality, and way of life, athletic performance and celebrity endorsement skill. The meaning of the attractiveness model as quoted by the famous philosopher Aristotle is that beauty becomes a greater recommendation than any letter of introduction. Aristotle emphasised beauty as of supreme importance since this attribute made those who were beautiful more attractive than others. Celebrity-based advertisements will increase consumer attitude towards celebrity and product or brand (Endogan, 1999) because celebrity endorsement by a person who projects good physical appearance in the advertising would be immensely attractive to target the consumer's mind and could potentially change his attitude (Joseph, 1982). Attractiveness of celebrity endorser infers advertisement recall and is sought to be associated to the consumer's intention to purchase (Hani, Marwan \& Andre, 2018). This is contradict with recent study by Azizi, Omar \& Ariffin (2019) which suggest that attractiveness does not related to purchase intention of Malaysia student.

According to Makgosa (2010), many teenagers look upon celebrities as their role model in order to support their desire and help them in their decision-making. Kahle (1985) opines that since physical attractiveness has a huge impact on consumer intention, using celebrities as endorsers in advertisements would thus become the best strategy to form positive attitudes on consumers' intention to imitate (Awasthi \& Choraria, 2015). Consumers desire to build a positive stereotype of the people surrounding them and communication through physical attractiveness would be more successful to change people's minds or beliefs to do something related with their attitude or behaviour (Baker \& Churchill, 1977; Chaiken, 1979; Debevec \& Keman, 1984; McCormic, 2016). In addition, Baker \& Churchill (1977); Thwaites, Lowe, Monkhouse \& Barnes (2012) suggest that consumers are likely to also be drawn to advertisements that project the attractive physical features of celebrity endorsers and automatically change consumers' attitude. Therefore it can be hypothetised that:

H1a There is a relationship between attractiveness and attitude towards imitating celebrity endorsement.

\section{Credibility}

According to Belch \& Belch (1994), credibility is defined as the extent to which the recipient sees the source as having relevant knowledge, skills and experience, and trusts this source to give unbiased and objective information. Credibility similarly could be defined as the believability of the addressor and how he or she is perceived in the listener's mind (Adler \& Rodman, 2000). Goldsmith, Lafferty \& Newell (2000) suggest that the credibility of an advertisement is affected by multiple factors such as credibility of firms and celebrity endorsers as the person bringing the message. Yilmaz, Telci, Bodur \& Iscioglu (2011) argue that a celebrity who has credibility is more effective on the target audience since they would draw more attention and effect on consumers' 
attitude towards celebrity endorsement behaviour compared to a celebrity with low credibility (Rai \& Sharma, 2013).

Laferty \& Goldsmith (1999) found the credibility of celebrity endorsement often used as a tactic in advertising to influence consumers' attitude with this type of endorsement having positive significant correlation with the advertisement's believability (Anjun, Dhanda, \& Nagra, 2012). The credibility of a source depends on the communicator's positive characteristics that affect the receiver's acceptance of the message (Ohanian, 1990). Many researchers suggest that organisations make their choice of celebrity endorsers based on their credibility to speak about products and brands in an advertisement (Gan, 2006; Rai \& Sharma, 2013). In many instances, consumers are drawn to their favourite celebrity because of his or her credibility so they look at the advertisement (Ahmed, 2014).

Apart from increasing the sales of a company, the credibility of celebrity endorsers in advertisements is a good strategy to increase customers' attitude and intention (Chan, 2013). Celebrities with high credibility value would be more effective in garnering the attention of consumers and subsequently influencing their attitude to change while those with low credibility would not affect any consumer attitudinal change (Yilmaz et al., 2011). Research conducted by Bhatt, Jayswal \& Patel, (2013) has proven that celebrity endorsement would have the credibility to draw customers. When consumers perceive credibility of the celebrity endorsement (Jatto, 2014), this in turn would attract more consumers to be influenced (Yilmaz et al., 2011). Therefore, the hypothesis here is:

H1b There is a relationship between credibility and attitude towards imitating a celebrity endorsement.

\section{Trustworthiness}

According to Erdogan, Baker \& Tagg (2001), trustworthiness refers to the honesty, integrity and believability of an endorser. Trust of consumers depends on what endorsers attempt to tell or deliver and this would have a huge impact whereby believability of the advertisement would positively help improve consumer attitude (Lane, 1988). Ibok (2013) argues that the effectiveness of celebrity endorsement is dependent on the trustworthiness level of the celebrity, and this factor merits serious consideration for advertisers when choosing their celebrities to endorse their product and ensure the effectiveness of the advertising they create.

In addition, the choice of a celebrity with a positive public image could help marketers improve their product acceptance among consumers (Ibok, 2013). The selection of a celebrity with a high degree of trustworthiness, honesty and affinity to endorse a brand and product is important to improve the advertisement performance (Erdem, 2004) since trustworthiness is a general believability of the endorser's behaviour (Low, 2012).

Consumers tend to have more trust and would be willing to pay a higher premium for a product if the celebrity endorsing that particular product or brand projects a positive image and is well-respected (Francis, 2013). Celebrity endorsement in an advertisement 
helps create trustworthiness in both existing and potential consumers, and at the same time increase brand or product awareness leading to positive recognition and association which could then serve to attract new consumers (Zipporah, 2014). Ohanian (1991) views trustworthiness as important for effective endorsement; when consumers believe what the celebrity endorser conveys to them in the advertisement and they have trust in him or her, the believability of the advertisement is higher and consumer acceptance would increase. The negative reporting or portrayal of a celebrity in the media affects the believability and trustworthiness of the celebrity endorsement which could adversely affect the brand image and sales of related products. Celebrity endorsement with a high trustworthiness score is able to change consumer attitude and purchase intention (Liu and Teo, 2007; McCormic, 2016). Aziz, Omar and Ariffin (2019) found that there is low relationship between trustworthiness and purchase intention. When consumers believe an endorser is credible, the perception would be that the information conveyed by this celebrity is true. However, when a celebrity endorses multiple products or brands, the trustworthiness of the celebrity endorsement becomes negative (Redenbach, 2005). Therefore, it could be hypothesised that:

H1c There is a relationship between trustworthiness and attitude towards imitating celebrity endorsement.

\section{Expertise}

According to Erdogan (1999), the expertise of celebrity endorsers is defined as the extent to which an endorser is perceived to be a source of valid assertions. Ohanian (1991), and Till and Busier (1998) argue that the endorsing celebrity should be an expert on that particular product or brand because this knowledge would serve to better convince the consumers compared to an endorser who does not have the expertise (Speck, Schumann, and Thompson, 1988). Silvera and Austad (2004) believe that celebrities with expertise are perceived as master on the products and thus able to convey to consumers the trustworthiness of their knowledge of the products they are endorsing (Dutta \& Singh, 2013). Ohanian (1990) goes one step further and theorises that expertise of the celebrity endorsement is not actually important - rather, it is more important for the consumers to perceive that their celebrity endorser possesses this expertise; in short, the consumers have to think and believe that the celebrity endorser has the expertise (Ohanian, 1990). Expert sources also influence perception of product quality with the source of celebrity endorsement specialist also a persuasive element (Aaker, 1997) and able to generate more purchase intentions (Ohanian, 1991). Speck, Schumann and Thompson (1988) add that celebrities who come across as experts in their specific areas would increase brand recognition more than celebrities who look like non-experts. The level of celebrity expertise would determine its effectiveness (Amos, Holmes, \& Strutton, 2008); celebrity endorsement with high expertise is able to change consumer attitude and purchase intention (Liu \& Teo, 2007). When celebrity endorsers demonstrate expertise in their field, consumers would have a favourable attitude towards the product, brand or advertisement (Aziz, Omar and Ariffin, 2019). Therefore, it could be hypothesised that:

H1d There is a relationship between expertise and attitude towards imitating celebrity endorsement.

\section{Individual Characteristics}




\section{Self-satisfaction}

Satisfaction could be defined as happiness that is derived from positive and good feelings about oneself and life (Ryff, 1989). Human beings seek self-satisfaction so as to make their life comfortable and peaceful in society since this affects physical and mental health; similarly, support from each other in terms of social interaction and the acquisition of a sense of belonging is critical (Aziz, Omar, \& Ariffin, 2019) since social relationship and the individual's feelings of isolation have been acknowledged as health predictors (Cacioppo, Hawkley, Crawford, Ernst, Burleson, \& Kowalewski, 2002). According to Baumeister (1991), among traditions, institution and self, the first two are found less influential as bearers of meaning compared to self. Awasthi and Choraria (2015) expand this theory further by positing that there are two meanings in self: (1) self as the agent responsible for the construction of meanings whereby the individual performs to attain something he or she is inspired by and at times attempts to adjust personal elements with the cultural elements to feel satisfaction, and (2) self and its development as the meaning and goal of life with the individual deriving pleasure from attaining some improvement in their self and avoiding some pain. This self-satisfaction would then be reflected in the consumer's attitude and behaviour in their personal life (Bavani \& Mohan, 2015). Anton (1996) defines satisfaction as a state of mind in which the needs, wants and expectations throughout for things or life have been met or exceeded, resulting in future repeated loyalty. In short, individuals attain selfsatisfaction when they achieve their desires. Katz (1960) reiterates that needs are fulfilled by attitude with some attitudes allowing a person to access circumstances in which rewards are available such as when expressing a liking for a particular way of dressing allows an adolescent to imitate interesting models (Malik \& Qureshi, 2016). Therefore, it could be hypothesised that:

H2a There is a relationship between self-satisfaction and attitude towards imitating celebrity endorsement.

\section{Expression of Power}

According to Choraria and Awasthi (2015), power could be described as an asymmetry in the relationship among individuals, a concept derived from the fields of political science, sociology and economics (Simon, 1953). Choi (2009) opines that the symbol of power and status reflected by a celebrity could influence the audience. Power could be due to an asymmetry in dependence (Emerson, 1962) and in image and knowledge (Noe, van Schaik, \& Hooff, 1991; Hand, 1986); this indicates that asymmetry in relationships is generally raised due to possession of an inalienable commodity such as those mentioned earlier (Raval \& Tanna, 2014). According to Anderson, John, and Keltner (2012), in the contexts of psychology, the concept of power could be defined as an insider who is able to influence other people. For Mooij (2011), power is the extent of less powerful members in society accepting and expecting power to be distributed unequally leading to some members becoming not confident and some societies avoiding their behaviour.

The power of celebrity endorsement could be determined based on their effectiveness in persuading consumers regardless of their interest (Knott, 2004). Power could affect advertising critically depending on the match between processing resources available to consumer and those demanded by advertising (Pieter, Wedel, \& Batra, 2010). In the 
context of international advertising, power could be affected when the advertisement focuses on the identification of the brand (Moriarty, 1986). The expression of power could be matched with the appeal of mass media which is often described as having a star-possessing universal popularity able to generate viewer intention to feel interested in mass media (Mberia, 2014; Malik \& Qureshi, 2016). Choosing celebrities of high reputation to front a brand or product would be a tactically good move (Charbonneau, 2010). According to Blackwell (2013), the expression of power is realised by way of brand or product testimonies with the celebrity as spokesperson for an extended period regardless of whether consumers have been attracted or not. Awasthi and Choraria (2015) suggest that consumers with their own personal expression of power towards their celebrity endorsement would give positive results on intention to imitate. In the context of society, individuals create and develop their self-identity (Bandura, 1977) and the regular appearance of celebrities on television with make-up, photo-editing, glamorous clothing, flattering lighting, surgery, and show-casing their luxurious cars, houses, jewelry and expensive possessions would inevitably motivate the consumer's intention to imitate (Chan \& Zhang, 2007). Celebrities equipped with their various advantages have the power to attract attitude change on the part of their fans. Endogan (1999) defines an attractive celebrity as one who has a good physical appearance and projects positive self-characteristics such as intellectual skills, personality, lifestyle, or athletic prowess. In numerous societies, the daily life of its members often reflects their status with the ranks obvious between the low and high levels (Malik \& Qureshi, 2016). Therefore it could be hypothesised that:

H2b There is a relationship between expression of power and attitude towards imitating celebrity endorsement.

\section{Attitude towards Imitating Celebrity Endorsements}

The success of Hallyu in becoming one of the biggest cultural phenomena across Asia is reflected when Korean celebrities become famous not only in their own country but also on the global entertainment scene. This universal acceptance and international recognition thus present to marketers the opportunity to appoint these famous celebrities as the face of their product or brand (Aziz, Omar, \& Ariffin, 2019). The celebrity endorser - an individual who enjoys public recognition and uses this recognition on behalf of consumer goods by appearing with it in an advertisement - has in recent years become very popular in modern marketing (McCracken, 1989; Choi \& Rifon, 2007). Consumers have been served with innumerable voices and images in magazines, newspapers, and on billboards, websites, radio and television (Anjun, Dhanda, \& Nagra, 2012) with consumers receiving in the excess of more than 3,000 commercial images per day showing over 150 images with about 30 of these reaching the conscious mind of users (Advertising Age, 2010). According to Mberia (2014); Malik \& Qureshi (2016), advertisements fronted by celebrities as brand or product ambassador would be more effective in attracting consumers and could generate millions in profit. Marketers have used celebrities in endorsements due to their ability to help their companies form unique advertising leading to a positive image on attitudes and increasing the sale of product or brand (Ranjbarian et al., 2010). Therefore it could be hypothesised here that:

H3 There is a relationship between attitude towards imitating celebrity endorsement and intention to imitate. 


\section{Intention to Imitate}

According to Mitchell (2014), humans learn through modelling others. Observations by Hoffman and Tan (2013) found that the relationship between attitude and desire have a significant impact on everyone, social relationships of celebrities to people who were watching openly and their good star quality made interaction reciprocity which is great with supernatural fans with them as para-social affiliations which enable them to display clearly in social networks and achieve great influence as advisor or can be imitated by the public. Rizzolatti, Fogassi and Gallese (2001) consider consumer intention as a complex process influenced by various internal and external factors such as individual personality and the image created by someone perceived to be wellknown. Users look for specific characters in their lives that impact their intention to make decisions directly or indirectly (Hoehl, Keupp, Schleihauf, McGuigan, Buttelmann \& Whiten, 2019). In this instance, the role model is the individual who has the qualities or behaviour that people admire and thus imitate (Meltzoff \& Williamson, 2017). Rizzolatti et al. (2001) opine that the individual's desire to emulate certain aspects of character or behaviour often stems from the perception of equality and aspiration with the imitation occurring mostly when people meet or watch a specific person especially models, TV celebrities, celebrity endorsements, athletes and others who are attractive and initiate the intention to imitate. In addition, Dautenhahn and Nehaniv (2002) explain that the important things between time and place could be points for the imitation to occur with the different surroundings being the factor of intention to imitate; however they have to personally determine their action in social interaction (Meltzoff \& Williamson, 2017). Awasthi and Choraria (2015) deem the imitation to be successful when they have made the process of imitation in the appropriate work and context in terms of who, when, where, how and what have initiated their intention to imitate. Therefore, it could be hypothesised that:

H4a Attitude toward imitating celebrity endorsement mediates the relationship between attractiveness and intention to imitate.

H4b Attitude toward imitating celebrity endorsement mediates the relationship between credibility and intention to imitate.

H4c Attitude toward imitating celebrity endorsement mediates the relationship between trustworthiness and intention to imitate.

H4d Attitude toward imitating celebrity endorsement mediates the relationship between expertise and intention to imitate.

H5a Attitude toward imitating celebrity endorsement mediates the relationship between self-satisfaction and intention to imitate.

H5b Attitude toward imitating celebrity endorsement mediates the relationship between expression of power and intention to imitate.

Figure 1: Research Model 


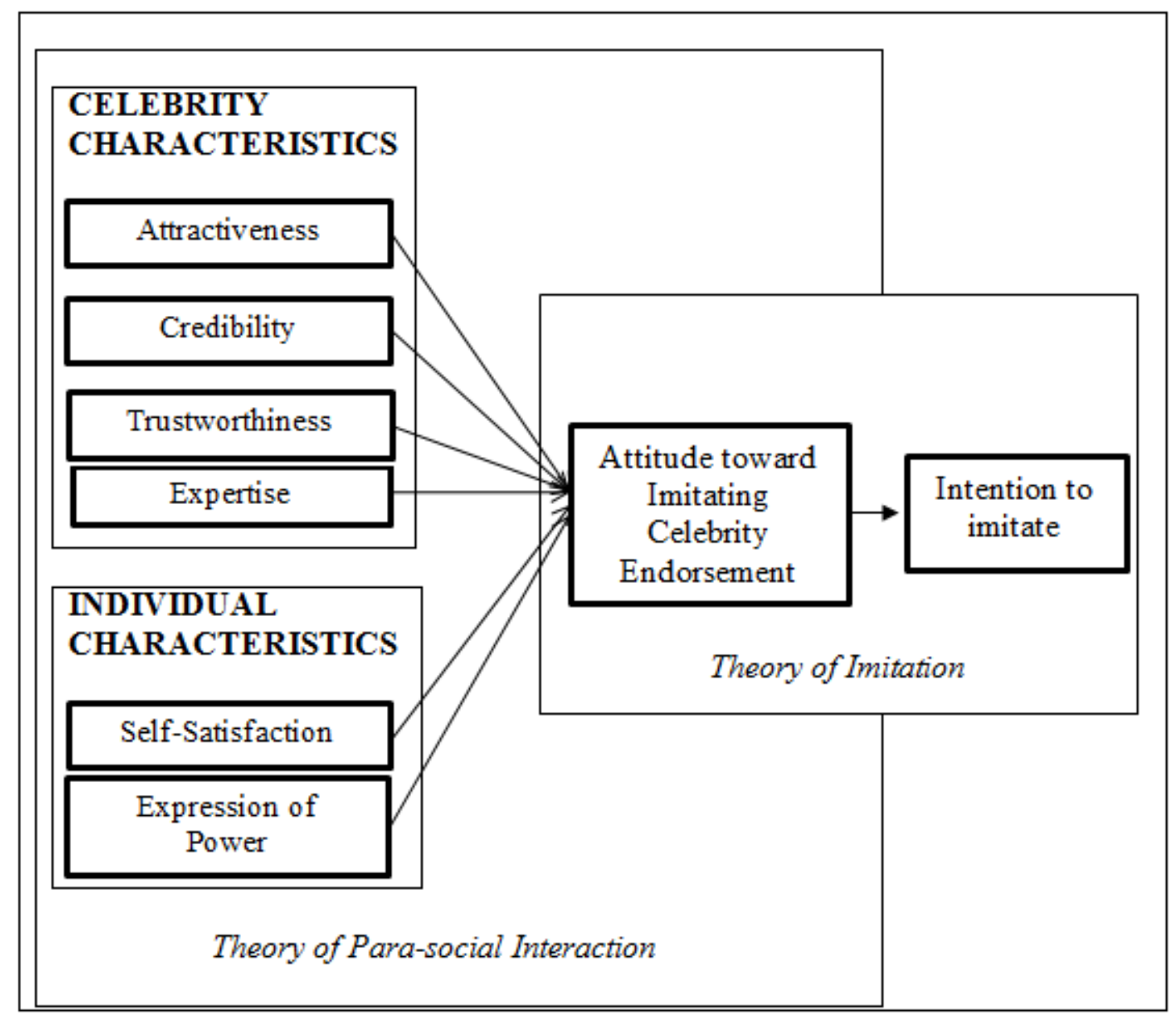

\section{Methodology}

\section{Participants}

The target populations for this study were individual males and females who had experience watching Korean celebrity endorsements or had been attracted to Korean celebrities. The respondents were classified according to age, gender, ethnicity, status and educational level. For the purpose of this study, a survey was conducted in 10 private and public universities in Peninsular Malaysia using a self-administered questionnaire. The $\mathrm{G}^{*}$ power 3.1 software was used to calculate sample size (Faul et al., 2007; 2009) with the setting as follows: $\mathrm{f} 2=0.02$ (small), $\alpha=0.05$, number of predictor $=6$, and power set at $80 \%$ (Gefen et al., 2011). The sample size required to test this model was 485; 50 responses therefore were collected from each university which presented a total sample size of 602 .

The respondents of this study were equally distributed between males (50\%) and females $(50 \%)$. In terms of age, only two age groups participated which were 18-23 (95.5\%) and 24-29 (4.5\%). The respondent breakdown for level of education was $18.3 \%$ (diploma), $70.1 \%$ (degree), $0.8 \%$ (master), $0.7 \%$ (PhD), and $10.1 \%$ (others). In terms of respondent ethnicity composition, the largest group was Malay (60.1\%) 
followed by Chinese (22.3\%), Indian (8.1\%), Bumiputera Sabah (4.8\%), Bumiputera Sarawak $(4.7 \%)$, and others $(0.2 \%)$.

\section{Measures}

The questionnaire was divided into Section A (demographic information) and Section B (attractiveness, credibility, trustworthiness, expertise, self-satisfaction, expression of power, attitude toward imitating celebrity endorsement, and intention to imitate). For 'attractiveness', the measurement was adopted from McGuire (1985), Ohanion (1990), Renton (2009), Emma and Matilde (2017) and Awasthi and Choraria (2015). Measurement for 'credibility' was derived from Erdogan, Baker and Tagg (2001), Renton (2009) and MacKenzie and Lutz (1989); 'trustworthiness' from Ohanian (1990), Awasthi and Choraria (2015) and Emma and Matilde (2017); 'expertise' from Ohanian (1990) and Spry, Pappu and Cornwell (2011); 'self-satisfaction' from Andrews and Withey (1976), Near, Rice and Hunt (1987), Awasthi and Choraria (2015) and Twenge and Campbell (2008); 'expression of power' from Pratto, Sidanius, Stallworth and Malle (1994), Xin and Chi (2010) and Awasthi and Choraria (2015); 'attitude toward imitating celebrity endorsement' from MacKenzie and Lutz (1989) and Awasthi and Choraria (2015); and 'intention to imitate' from Ohanian (1990), Chan and Prendergast (2008) and Awasthi and Choraria (2015).

Respondents were asked to indicate their experience with Korean celebrity endorsements through several statements on a 5-point Likert scale ranging from $1=$ strongly disagree to $5=$ strongly agree. The items used to measure self-satisfaction, expression of power, attitude toward imitating celebrity endorsement, and intention to imitate were adapted from established past studies.

\section{Findings}

\section{Reliability and Validity}

Table 3 represents the square root of the average variance extracted and the correlations between the constructs for measurement model. The square root of AVE was greater than the correlation with any other construct. With regards to cross loading, Hair, Ringle and Sarstedt (2013) suggest that the loading should be higher than the cross loading by at least 0.1 to indicate adequate discriminant validity. As indicated in Table 4, the loading of all constructs fulfilled this criterion. Overall, the measurement model in this study was shown to be satisfactory with evidence of adequate reliability, convergent validity and discriminant validity.

Table 1: Convergent Validity

\begin{tabular}{lccccc}
\hline Construct & Item & Loading & $\begin{array}{c}\text { Cronbach's } \\
\text { Alpha }\end{array}$ & CR & AVE \\
\hline Intention to Imitate & Iti1 & 0.849 & 0.868 & 0.905 & 0.658 \\
& Iti2 & 0.720 & & & \\
\hline
\end{tabular}




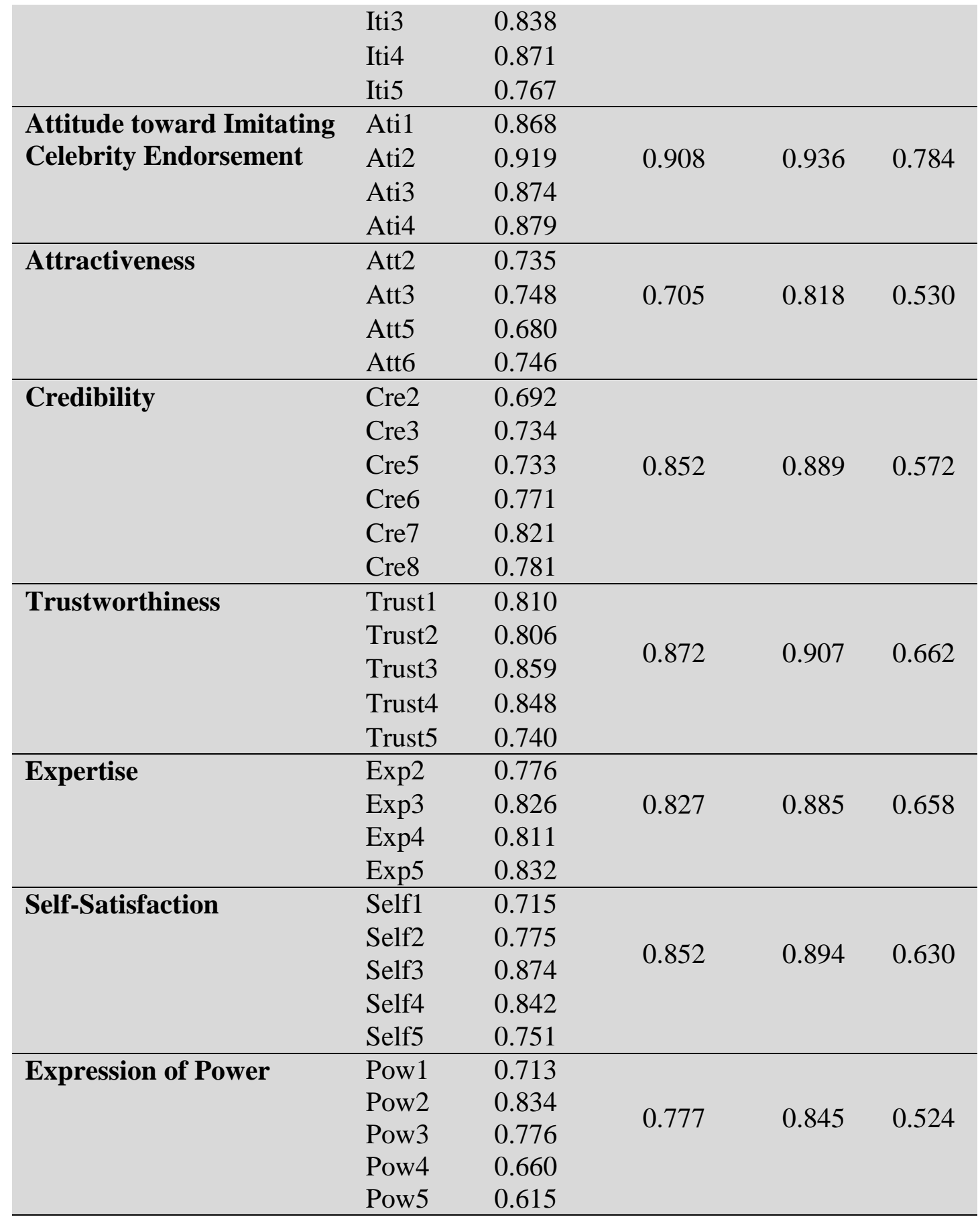

\section{Deleted Items and Convergent Validity}

Various measurement items were used to predict the value of variables suggested in this study. However, after the data was run using Smart-PLS software (Ringle, Wende \& Will, 2005), several measurement items with low values were deleted so as to 
improve the value of Average Variance Extracted (AVE). Therefore, the items (att1) "the celebrity who appeared in the advertisement is physically attractive", (att4) "the celebrity used in the advertisement should look classy", (cre1) "the celebrity who appeared in the advertisement seems responsible" and (pow6) "I think we should do what we can to achieve our desire" were deleted due to poor loading $<0.650$ (Hair et al., 2014). No other item was subsequently deleted based on the assertion by Hair et al. (2014) that further deletion of item would be unnecessary when AVE > 0 .

The convergent validity of the measurement is usually ascertained by examining the loading, Average Variance Extracted (AVE) and composite reliability (Gholami et al., 2013; Rahman et al., 2015). The loadings were all found higher than 0.708, composite reliabilities all higher than 0.7 and AVE of all constructs also higher than 0.5 , as suggested in the literature (Figure 2 and Table 3).

\section{Discriminant Validity}

Recent criticism has suggested that the Fornell-Larcker (1981) criterion does not reliably detect the lack of discriminant validity in common research situations (Henseler et al., 2015) (Table 4) and proposed instead an alternative approach, based on the multitrait-multimethod matrix, to assess discriminant validity in the form of heterotraitmonotrait ratio of correlations. Henseler et al. (2015) also go on to demonstrate the superior performance of this method by means of a Monte Carlo simulation study. As such, this research also tested the discriminant validity using this new suggested method with the results shown in Table 5. When the HTMT value is greater than HTMT0.85 value of 0.85 (Kline, 2011) or HTMT0.90 value of 0.90 (Gold et al., 2001), this then poses a problem in discriminant validity; however, as all the values passed the HTMT0.90 (Gold et al., 2001) and also the HTMT0.85 (Kline, 2011) as shown in Table 5 , this thus indicated that discriminant validity had been ascertained.

Table 2: Discriminant Validity (Fornell and Lacker's Criterion)

\begin{tabular}{|c|c|c|c|c|c|c|c|c|}
\hline \multicolumn{9}{|c|}{ Fornell And Lacker Criterion } \\
\hline & $\begin{array}{l}\text { Attitud } \\
\text { e }\end{array}$ & $\underset{t}{\text { Attrac }}$ & Cred & $\begin{array}{c}\text { Exper } \\
t\end{array}$ & $\begin{array}{c}\text { Powe } \\
\mathbf{r}\end{array}$ & $\begin{array}{c}\text { Intentio } \\
\mathbf{n}\end{array}$ & Satis & $\begin{array}{c}\text { Trus } \\
\mathbf{t}\end{array}$ \\
\hline Attitude & 0.885 & & & & & & & \\
\hline Attract & 0.409 & 0.728 & & & & & & \\
\hline Cred & 0.396 & 0.442 & $\begin{array}{c}0.75 \\
6\end{array}$ & & & & & \\
\hline Expert & 0.374 & 0.318 & $\begin{array}{c}0.56 \\
7\end{array}$ & 0.811 & & & & \\
\hline Power & 0.443 & 0.260 & $\begin{array}{c}0.35 \\
1\end{array}$ & 0.348 & 0.724 & & & \\
\hline $\begin{array}{l}\text { Intentio } \\
\mathbf{n}\end{array}$ & 0.596 & 0.453 & $\begin{array}{c}0.32 \\
6\end{array}$ & 0.293 & 0.402 & 0.811 & & \\
\hline Satis & 0.705 & 0.464 & $\begin{array}{c}0.53 \\
6\end{array}$ & 0.540 & 0.461 & 0.530 & $\begin{array}{c}0.79 \\
4\end{array}$ & \\
\hline Trust & 0.453 & 0.383 & $\begin{array}{c}0.73 \\
5\end{array}$ & 0.572 & 0.300 & 0.299 & $\begin{array}{c}0.56 \\
3\end{array}$ & 0.813 \\
\hline
\end{tabular}


Table 3: Discriminant Validity (HTMT Criterion)

\begin{tabular}{l|c|c|c|c|c|c|c}
\hline \multicolumn{7}{c}{ HTMT Criterion } \\
\hline & Attitude & Attract & Cred & Expert & Power & Intention & Satis \\
\hline Attract & 0.502 & & & & & & \\
Cred & 0.435 & 0.584 & & & & & \\
Expert & 0.430 & 0.425 & 0.668 & & & & \\
Power & 0.501 & 0.338 & 0.428 & 0.429 & & & \\
Intention & 0.667 & 0.576 & 0.380 & 0.345 & 0.469 & & \\
Satis & 0.794 & 0.597 & 0.622 & 0.644 & 0.541 & 0.611 & \\
Trust & 0.507 & 0.498 & 0.840 & 0.672 & 0.362 & 0.343 & 0.655 \\
\hline
\end{tabular}

\section{Test of Structural Relationships Results}

To assess the structural model, Hair et al. (2017) suggest examining the R2, beta $(\beta)$ and the corresponding t-values via a bootstrapping procedure with a resample of 5000 . In addition to these basic measures, the predictive relevance (Q2) as well as the effect size (f2) should also be reported. As asserted by Sullivan and Feinn (2012), while a pvalue might inform the reader whether an effect exists, the p-value however would not reveal the size of this effect. In reporting and interpreting studies, both the substantive significance (effect size) and statistical significance ( $p$-value) are essential results to be reported.

Figure 2: Bootstrapping Result

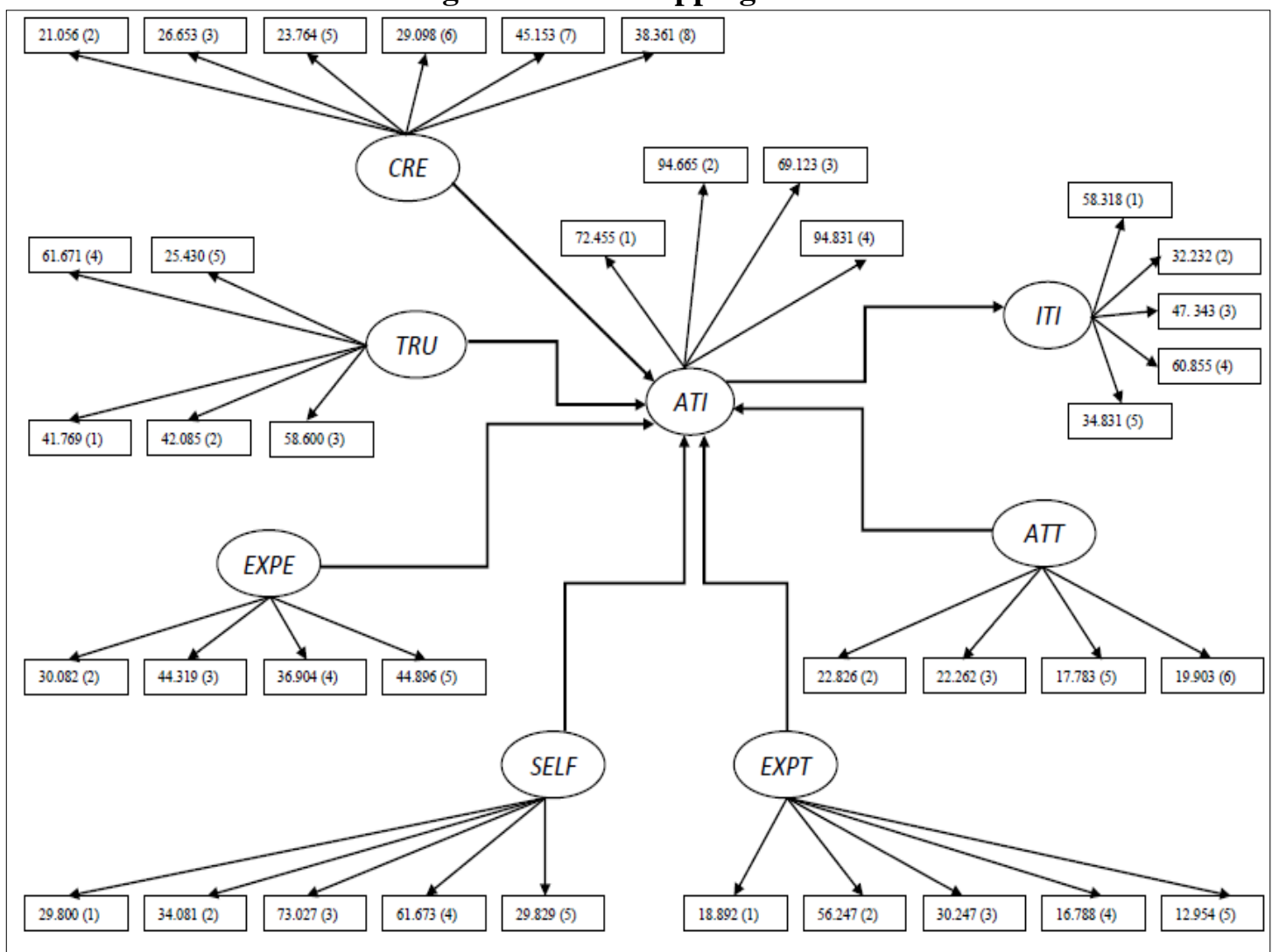


As suggested, in this study the effect size and confidence intervals are included as part of the reporting (Table 4): attractiveness $>$ attitude toward imitating celebrity endorsement $(\beta=0.100, \mathrm{t}=2.952, \mathrm{p}<0.01, \mathrm{f} 2=0.005)$, trustworthiness $>$ attitude toward imitating celebrity endorsement $(\beta=0.129, \mathrm{t}=2.515, \mathrm{p}<0.01, \mathrm{f} 2=0.550)$ (onetailed), expression of power $>$ attitude toward imitating celebrity endorsement $(\beta=$ $0.155, \mathrm{t}=3.973, \mathrm{p}<0.01, \mathrm{f} 2=0.039)$ (one-tailed), self-satisfaction $>$ attitude toward imitating celebrity endorsement $(\beta=0.589, \mathrm{t}=13.455, \mathrm{p}<0.01, \mathrm{f} 2=0.550)$ (onetailed), and attitude towards imitating celebrity endorsement $>$ intention to imitate $(\beta=$ $0.596, \mathrm{t}=17.356, \mathrm{p}<0.05, \mathrm{f} 2=0.015$ ) (one-tailed). All these relationships were significant to explain the $53.0 \%$ of the variance in usage, and support $\mathrm{H} 1 \mathrm{a}, \mathrm{H} 1 \mathrm{c}, \mathrm{H} 2 \mathrm{a}$ $\mathrm{H} 2 \mathrm{~b}$ and $\mathrm{H} 3$.

However, since credibility $>$ attitude toward imitating celebrity endorsement $(\beta=$ $0.081, \mathrm{t}=1.580, \mathrm{p}<0.05, \mathrm{f} 2=0.013$ ) (one-tailed) and expertise $>$ attitude toward imitating celebrity endorsement $(\beta=-0.058, \mathrm{t}=1.350, \mathrm{p}<0.010, \mathrm{f} 2=0.004)$ (onetailed), it therefore could be concluded that $\mathrm{H} 1 \mathrm{~b}$ and $\mathrm{H} 1 \mathrm{~d}$ are not supported with both these relationships deemed insignificant in explaining the $53.0 \%$ of the variance in usage.

Table 4: Results of Direct Effect

\begin{tabular}{c|c|c|c|c|c|c}
\hline Relationship & Beta & S.E. & T-Value & $\mathbf{F}^{\mathbf{2}}$ & P-Value & $\mathbf{R}^{\mathbf{2}}$ \\
\hline Attitude -> Intention & 0.596 & 0.034 & 17.356 & 0.015 & 0.000 & 0.530 \\
Attract-> Attitude & 0.100 & 0.034 & 2.952 & 0.005 & 0.002 & \\
Cred -> Attitude & -0.081 & 0.051 & 1.580 & 0.013 & 0.057 & \\
Expert -> Attitude & -0.058 & 0.043 & 1.350 & 0.004 & 0.089 & \\
Power -> Attitude & 0.155 & 0.039 & 3.973 & 0.039 & 0.000 & \\
Satis -> Attitude & 0.589 & 0.044 & 13.455 & 0.372 & 0.000 & \\
Trust -> Attitude & 0.129 & 0.051 & 2.515 & 0.550 & 0.006 & 0.355 \\
\hline
\end{tabular}

The predictive effects on the intention to imitate (Table 5) were then examined whereby attractiveness $>$ intention to imitate $(\beta=0.060, \mathrm{t}=2.758, \mathrm{p}<0.01)$ (two-tailed), trustworthiness $>$ intention to imitate $(\beta=0.077, \mathrm{t}=2.508, \mathrm{p}<0.01)$ (two-tailed), expression of power $>$ intention to imitate $(\beta=0.093, \mathrm{t}=3.845, \mathrm{p}<0.01)$ (twotailed)and self-satisfaction $>$ intention to imitate $(\beta=0.351, \mathrm{t}=10.647, \mathrm{p}<0.01)$ (twotailed). All these relationships were found to be significant predictors of intention to imitate explaining $35.5 \%$ of the variance in usage. Since credibility $>$ intention to imitate $(\beta=-0.048, \mathrm{t}=1.567, \mathrm{p}<0.05)$ (two-tailed) and expertise $>$ intention to imitate $(\beta=-0.034, \mathrm{t}=1.342, \mathrm{p}<0.10)$ (two-tailed), both relationships were insignificant predictors of intention to imitate explaining $35.5 \%$ of the variance in usage. These findings support $\mathrm{H} 4 \mathrm{a}, \mathrm{H} 4 \mathrm{c}, \mathrm{H} 5 \mathrm{a}$ and $\mathrm{H} 5 \mathrm{~b}$ while $\mathrm{H} 4 \mathrm{~b}$ and $\mathrm{H} 4 \mathrm{~d}$ are not supported.

Table 5: Results of Mediation Effect

\begin{tabular}{l|c|c|c|c}
\hline \multicolumn{1}{c|}{ Relationship } & Beta & S.E. & T-Value & P-Value \\
\hline Attract -> Intention & 0.060 & 0.022 & 2.758 & 0.003 \\
Cred -> Intention & -0.048 & 0.031 & 1.567 & 0.059 \\
Expert -> Intention & -0.034 & 0.026 & 1.342 & 0.090 \\
Power -> Intention & 0.093 & 0.024 & 3.845 & 0.000 \\
Satisfaction -> Intention & 0.351 & 0.033 & 10.647 & 0.000 \\
Trust -> Intention & 0.077 & 0.031 & 2.508 & 0.006 \\
\hline
\end{tabular}




\section{Discussion}

For marketers planning to use celebrities as endorsers to promote their product or brand, this study has identified several assistive factors such as celebrity characteristics (attractiveness, credibility, trustworthiness and expertise) and consumer individual characteristics (self-satisfaction and expression of power). However, marketers should exercise care since not all the characteristics would positively affect consumers' attitude and intention. As explained below, marketers could take these into consideration in their selection of the celebrity most suitable to endorse a particular product or brand.

The attractiveness of an endorsing celebrity would be very good for marketers in maintaining and improving the consumers' attachment towards all types of products or brands in advertisements. Celebrity endorsement is attractive because it projects traits such as their good looks or beauty, body shape and physical appearance.

The credibility of a celebrity refers to the extent at which this person is trusted or seen as believable by the audience or target market (Ibok, 2013). In fact, consumers would actually view this celebrity as someone who brings the message from that firm; this therefore means he or she must understand the firm clearly (Kahlle and Pamela, 1985). Consumers would automatically perceive the celebrity who appears in the endorsement advertisement as credible (Dwivedi, Mcdonald, \& Johnson, 2014). In addition, building credibility in the market is acknowledged as vital to a company's advertising effectiveness with celebrity endorsement necessary and celebrities investing considerable effort towards maintaining a good public image for their consumers (Kahlle \& Pamela, 1985; Ibok, 2013) This is consistent with the findings of Ohanian (1990), Pompitakpan (2003) and Silvera and Benedikte (2003).

The trustworthiness characteristic has the power to manipulate and change a consumer's attitude and subsequently lead to the intention to imitate the endorsing celebrity. The result is supported by Ibok (2013). When there is a high level of trust towards a celebrity, customers become more appreciative and would continue to patronise the endorsed product or service thereby fostering more advertising effectiveness. This assertion is consistent with the findings of Mowen and Stephen (1981).

In advertisements, the level of the expertise characteristic at times could not be assumed as the best factor to measure or predict the $100 \%$ effectiveness of celebrity endorsement or even to influence the consumer's attitude or intention. Although this is contradicted by results obtained by Ibok (2013) where he argues that when the level of expertise exhibited by a celebrity is high, the likelihood of success would also be similarly high; however if the level of expertise is low the acceptance would not be good from either the consumer or audience because the consumer or audience watching the celebrity endorsing a product or brand in an advertisement does not focus on the celebrity's expertise alone but also on other factors such as attractiveness of physical appearance and trustworthiness which might be more influential in generating attitude change and intention to imitate (Meltzoff \& Williamson, 2017). Till (2004) views mere expertise as not enough for a celebrity to appear in advertisements; they must also provide value for the customers and give them reasons to appreciate the advertisement.

Customer self-satisfaction is critical and highly impacts consumer attitude (Awasthi and Choraria, 2015). People derive self-satisfaction from celebrity endorsers who 
project good personality and are interesting. This is similarly true in advertisements: celebrities who are well-equipped with things would look good in the eyes of the consumer or audience, and provide the consumers with feelings of self-satisfaction (Howard, Henderson, Carrazza \& Woodward, 2015). This implies that an advertisement that stimulates the intention to imitate a celebrity (whose behaviour is imitated by the public), would be effective for self-satisfied customers (Awasthi \& Choraria, 2015).

Consumers generally have their own expression towards things that would influence their attitude and intention to support their decisions. The consumer's expression of power directly impacts the attitude towards the celebrity advertisement (Awasthi \& Choraria, 2015). Celebrities have the ability to attract consumers and this would be a good strategy to stimulate consumer attitude and intention to imitate what is being endorsed in an advertisment (Bergkvist, Hijalmarson, \& Magi, 2016).

\section{Managerial Implications}

This study has contributed to the literature in marketing by examining the role of consumer intention to imitate Korean celebrity-endorsed advertisements. Many previous studies investigated consumer socialisation and advertising such as consumer purchase intention and purchase behaviour. In this study the role of consumer attitude change which affects the intention to imitate in the context of celebrity endorsement is explored and has demonstrated that the consumer's attitude towards imitating celebrity advertisement as important in shaping the intention to imitate.

This study presents two implications theoritically: first, the theory of para-social interaction is an illusory face-to-face interaction that occurs when media viewers have to interact with their media figures. In this study, the researcher puts this theory in the context of interaction between consumer and celebrity endorsement in an advertisement that stimulates the consumer's desire to imitate so as to be similar to the celebrity whereby without doubt media viewers are affected in terms of changing their attitude towards imitating the celebrity endorsement. This in effect then is a new research contribution since no previous studies had used the para-social interaction theory to support their study in the context of celebrity endorsements that result in imitation.

The second implication here is that the theory of imitation used in this study is to support the relationship between attitude towards imitating celebrity endorsement and intention to imitate. The theory of imitation proposes that the suggestion-imitation is the repetition of a person's act by another under the influence of the suggestion offered. This means then that people would sometimes transform themselves to be someone good-looking or make their appearance attractive to other people. The suggestion offered is the attractiveness of modelling on other people, so that other people would feel attracted and amplifies the intention to be similar to the model they see.

For practitioners, three main findings are presented by this study: first, the choice of celebrity is important for different segments of customers. For instance, marketers find it critical to select a celebrity who possesses attractiveness and trustworthiness because consumers would be affected by their attitude toward the endorsement and increase their intention to imitate that particular personality. The advertisement has the potential 
to succeed if customers derive self-satisfaction and expression of power from the endorsing celebrity. Second, celebrity advertisements need to be created in ways that stimulate the consumer's intention to imitate thus increasing their purchase of the endorsed product or brand. Third, the study reinforces the importance of attitude towards imitating celebrity advertisements. When advertisements create a positive attitude towards the endorsing celebrities, this would then add to the intention to imitate on the part of customers.

\section{Further Research}

This study presented several limitations in testing all the independent variables that had been tested in past research since it could potentially turn into a massive framework with various hypotheses. All of these would then have to be tested, and as such would prolong the duration and hinder the completion of the research. The current study thus only examined several independent variables and separated these into two categories such as celebrity characteristic consisting attractiveness, credibility, trustworthiness and expertise, and individual characteristic consisting self-satisfaction and expression of power.

The current study also highlighted a mediator variable (attitude towards imitating celebrity endorsement) and a dependent variable (intention to imitate). Although previous studies tested the relationship of direct effect and indirect effect between factors to gauge the effectiveness of celebrity and attitude and behaviour, they still lacked prediction. This is based on the study by Awasthi and Choraria (2015) whereby their conceptual framework that tested imitation behaviour had impacted attitude towards celebrity and purchase behaviour. However in terms of the conceptual framework proposed in the theory of reasoned action, attitude is most likely the first cause to affect the attitude leading to intention, and the behaviour or action. Therefore, further studies in this instance could utilise a different indicator or all the indicators suggested by past research to test the effectiveness of celebrity endorsement, and at the same time should focus on predicting attitude, intention and behaviour whether directly or indirectly affecting the hypothesis. The application of theories proposed by past researchers is important in order to support any new conceptual framework. Without support by previous related studies, there is bound to be difficulties to operationalise their conceptual framework with researchers predicting the wrong outcomes on variables especially in the context of social science research. Many reliable theories could be used to support the conceptual framework proposed for further research. Therefore, future researchers should exercise care in the selection of theory to support their study.

In conclusion, for a bigger contribution in further studies, researchers could conduct a new study utilising a qualitative approach since the quantitative method by the current researcher has highlighted some lack in the data collection process resulting from respondents possibly not answering the questionnaire items accurately. For further research based on the qualitative approach, researchers and respondents could engage in face-to-face sessions and all conversations recorded, transcribed and translated at a later stage. 


\section{Implications for Asian Business Context}

This study provides further understanding on how celebrity endorsement could influence the Asian business, particularly consumers in the South East Asia region. The South East Asian consumers are relatively young (60\% of the population are less than 35 years old), as reported in a recent Nielson report (2019). Importantly, the young consumer market represents a huge potential market as they are more confident financially and believe that they are able to spend comfortably (Nielson report, 2019). The findings of this study confirmed the importance roles of individual and celebrity characteristics in influencing the attitude and eventually, the intention to imitate among young consumers. These results are consistent with Phang, Abdul Adis \& Osman (2018) who found Malaysian consumers to have positive attitudes to use, buy, share info and even portray overt behaviors implied by the hours spent on Korean wave products, info sharing behavior as well as choice of medium. It is important for marketers to choose celebrity endorsers who are attractive and trustworthy. In addition, this study also influence the South Korean products into global market as it would increase the promotion of Korean goods and tourism industry. The success of Korean Wave has contributed billions of U.S. dollars for the Korean Treasury and also accelerated the sales of Korean cars, mobile phones and fashion products in many different parts of the globe (Elaskary, 2018). For example, cosmetic and beauty products, which are intensively advertised by famous Korean celebrity, are affected directly from Korean wave (Chang \& Lee, 2017). In tourism industry, a number of 'Korean Wave' tourism destinations have emerged over the past decade in Korea due to the dramas, popular K-pop music videos, and their concerts by increased of $13 \%$ every year from 2009 to 2012 (Chang \& Lee, 2017). This indicates that, by highlighting every Asian cultures to the audiences through attractive segment in televisions or other entertainment programs, Asian business would be able to influence young consumer preference and ultimately their purchase decision.

\section{Acknowledgement}

This work was supported by seed Programme for Korean Studies through the Ministry of Education of Republic of Korea and Korean Studies Promotion Service of The Academy of Korean Studies (AKS-2015-INC-2230002).

This paper is presented in the 2018 MAG Scholar Conference in Global Business, Marketing and Tourism, Sarawak.

\section{References}

Aaker, J. L., (1997), "Dimensions of brand personality", Journal of Marketing Research, vol. 34, pp. 347-356.

Adler, R. B., \& Rodman, G., (2000), Understanding human communication, Harcourt College Publisher, Texas.

Ahmed, N., Farooq, O., \& Iqbal, J., (2014), "Credibility of celebrity endorsement and buying intentions and evidence from students of Islamabad, Pakistan", International Letters of Social and Humanistic Sciences, vol. 20, pp. 1-13. 
Amos, C., Holmes, G., \& Strutton, D., (2008), "Exploring the relationship between celebrity endorser effects and advertising effectiveness: A quantitative synthesis of effect size", International Journal of Advertising, vol. 27, no. 2, pp. 209-234.

Anjum, B., \& Dhanda, S. K., (2012), "Impact of celebrity endorsed advertisements on consumers", Asia Pacific Journal of Marketing and Management Review, vol. 1, no. 2, pp. 1-20.

Anderson, C., John, O. P., \& Keltner, D., (2012), “The personal sense of power”, Journal of Personality, vol. 80, no. 2, pp. 314-344.

Anton, J., (1996), Customer relationship management, Prentice-Hall Inc., New Jersey.

Ariffin, J. T., Abu Bakar, H., \& Yusor, N. H., (2018), "Culture in Korean drama towards influencing Malaysian audiences", International Journal of Innovative Research in Engineering \& Management, vol. 5, no. 1, pp. 10-14.

Ariffin, Z. Z., Othman, K., \& Abdullah, R. T., (2013), "Analyzing the dimension of Korean popular culture among Malaysian adolescent", 5th International Conference on Humanities and Social Science, pp. 11-35.

Awasthi, A. K., \& Choraria, S., (2015), "Effectiveness of celebrity endorsement advertisement: The role of consumer imitation behavior", Journal of Creative Communication, vol. 10, no. 2, pp. 215-234.

Aziz, Z. D. A., Omar, M. K., \& Ariffin, S., (2019), "The effects of celebrity endorsement towards purchase intention among students in one public university in Malaysia", International Journal of Academic Research Business and Social Sciences, vol. 9, no. 5, pp. 498-507.

Baker, M. J., \& Churchill, G. A., (1977), "The impact of physically attractive models on advertising evaluations", Journal of Marketing Research, vol. 14, pp. 538-555.

Baldwin, J. M., (1925), Mental development in the child and the race, MacMillan, New York.

Baumeister, R. F., (1991), Meanings of life, The Guilford Press, New York.

Bavani, S., \& Mohan, R., (2015), "Self-satisfaction and psychological well-being of academicians at private universities in Malaysia", International Journal of Novel Research in Education and Learning, vol. 2, no. 3, pp. 60-70.

Bergkvist, L., Hjalmarson, H., \& Magi, A., (2016), "A new model of how celebrity endorsements work: Attitude toward the endorsement as a mediator of celebrity source and endorsement effects", International Journal of Advertising, vol. 35, no. 2, pp. 171184.

Bhatt, N., Jayswal, R., \& Patel, J., (2013), "Impact of celebrity endorser's source credibility on attitude towards advertisements and brands", South Asian Journal of Management, vol. 20, no. 4, pp. 74-95.

Bush, A. J., Martin, C. A., \& Bush, V. D., (2004), "Sports celebrity influence on the behavioural intentions of generation Y", Journal Of Advertising Research, vol. 6, pp. 108-117.

Bok-rae, K., (2015), "Past, present and future of Hallyu (Korean Wave)", American International Journal of Contemporary Research, vol. 5, no. 5, pp. 154-160.

Cacioppo, J. T., Hawkley, L. C., Crawford, E., Ernst, J. M., Burleson, M. H., \& Kowalewski, R. B., (2002), "Loneliness and health: Potential mechanisms", Journal of Psychosomatic Medicine, vol. 64, pp. 407-417.

Chaiken, S., (1979), "Communicator physical attractiveness and persuasion", Journal of Personality and Social Psychology, vol. 37, pp. 1387-1397.

Chan, K., Leung Ng, Y., \& Luk, E., (2013), "Impact of celebrity endorsement in advertising on brand image among Chinese adolescent", Journal of Young Consumers, vol. 14, no. 2, pp. 167-179.

Chan, K., \& Zhang, (2007), "Living in a celebrity mediated social world: The Chinese experience", Young Consumers, vol. 8, no. 2, pp. 139-152.

Charbonneau, J., G. R., (2010), "Product effects on endorser image: The potential for reverse image transfer", Asia Pacific Journal of Marketing and Logistics, vol. 22, no. 1, pp. 101110.

Choi, S. M., Rifon, N. J., (2007), "Who is the celebrity in advertising? Understanding dimensions of celebrity images", Journal of Popular Culture, vol. 40, no. 2, pp. 304-324. 
Conrad, E., (1995), Caution: Falling idols; Ad Firms growing wary of tainted sports heroes, Post-Gazette, Pittsburgh.

Debevec, K., \& Keman, J. B., (1984), "More evidence on the effects of a presenter's physical attractiveness: Some cognitive, affective and behavioral consequences", Journal of Advances in Consumer Research, vol. 9, pp. 127-132.

Dwivedi, A., McDonald, R., \& Johnson, L., (2014), "The impact of a celebrity endorser's credibility on consumer self-brand connection and brand evaluation", Journal of Brand Management, vol. 21, no. 7-8, pp. 559-578.

Egan, J., (2007), Marketing communications, Thomson Learning, London.

Ellwood, C. A., (1901), "The theory of imitation in social psychology", American Journal of Sociology, vol. 66, pp. 721-741.

Erdem, S., (2004), "Brand credibility, brand consideration, and choice", Journal of Consumer Research, vol. 31, no. 1, pp. 191-198.

Erdogan, B. Z., Baker, M. J., \& Tagg, S., (2001), "Selecting celebrity endorsers: The practitioner's perspective", Journal of Advertising Research, vol. 41, no. 3, pp. 39-48.

Francis, R. Y., (2013), "The impact of celebrity endorsement and its influence through different scopes on the retailing business across United States and Asia", International Journal of Commerce, Business, and Management, vol. 2, no. 1, pp. 1-6.

Freiden, J. B., (1984), “Advertising spokesperson effects an examination of endorser type and gender on the audience", Journal of Advertising Research, vol. 24, no. 5, pp. 53-41.

Friedman, H. H., \& Friedman, L., (1979), "Endorser effectiveness by product type”, Journal of Advertising Research, vol. 19, no. 5, pp. 63-71.

Gan, W., (2006), "Effectiveness of celebrity endorsement advertising in Chinese marketplace", Dissertation for MA Marketing, pp. 1-89.

Gauns, K. K., Pillai, S. K. B., Kamat, K., Chen, R. F., \& Chang, L. C., (2018), "Impact of celebrity endorsement on consumer buying behaviour in the state of Goa", IIM Kozhikode Society \& Management Review, vol. 7, no. 1, pp 45-58.

Gentry, J. H., \& Campbell, M., (2002), "Developing adolescents: A reference for professionals", American Psychological Association, pp. 2-41.

Gholami, R., Sulaiman, A. B., Ramayah, T., \& Molla, A., (2013), "Senior managers' perception on green Information Systems (IS) adoption and environmental performance: Results from a field survey", Journal of Information and Management, vol. 50, no. 7, pp. 431438.

Goldsmith, R. E., Lafferty, B. A., \& Newell, S. J., (2000), "The impact of corporate credibility and celebrity credibility on consumer reaction to advertisements and brands", Journal of Advertising, vol. 29, no. 3, pp. 43-54.

Giles, D. C., (2002), "Para-social interaction: A review of the literature and a model for future research", Journal of Media Psychology, vol. 4, pp. 279-305.

Hani, S., Marwan, A., \& Andre, A., (2018), "The effect of celebrity endorsement on consumer behavior: Case of the Lebanese jewelry industry", Arab Economic and Business Journal, vol. 13, pp. 190-196.

Hsu, H., (2012), "Korean TV soap operas in Taiwan: An investigation of consumers' clothing purchase behavior", International Journal of Marketing Studies, vol. 4, no. 3, pp. 16-30.

Jin, B., \& Jeong, S., (2010), "The impact of Korean television drama viewership on the social perceptions of single life and having fewer children in married life", Asian Journal of Communication, vol. 20, no. 1, pp. 17-32.

Jung-Kim, J., (2014), My sassy girl goes around the world, Palgrave Macmillan, New York.

Kahle, L. R., \& Homer, R. M., (1985), "Physical attractiveness of celebrity endorser: A social adaptation perspective", Journal of Consumer Research, vol. 11, pp. 954-961.

Katz, D., (1960), "The functional approach to the study of attitudes", Public Opinion Quarterly, vol. 24 , no. 24 , pp. 163-204.

Khan, A., \& Lodhi, S., (2016), "Influence of celebrity endorsement on consumer purchase decision: A case of Karachi”, Imperial Journal of Interdisciplinary Research, vol. 2, no. 1, pp. 102-111. 
Knott, O. J. L., (2004), “An alternative approach to developing a total celebrity endorser rating model using the analytic hierarchy process", International Transactions in Operational Research, vol. 11, no. 1, pp. 87-95.

Lafferty, B., \& Goldsmith, R. E., (1999), "Corporate credibility's role in consumers attitudes and purchase intention when a high versus a low credibility endorser is used in the ad", Journal of Business Research, vol. 44, pp. 109-116.

Lane, F., (1988), Introduction theories and issues in the study of trust, Oxford University, Oxford.

Low, S-F., \& Lim, S-W., (2012), "Impact of the celebrity endorser on Malaysian young consumers: An empirical study in the sport industry", vol. 5, no. 1, pp. 95-114.

Liu, J., Teo, T. S. H., (2007), "Consumer trust in e-commerce in the United States, Singapore and China", Omega, vol. 35, pp. 22-38.

Liu, T., M., Huang, Y., \& Minghua, J., (2007), "Relations among attractiveness of endorsers, match-up, and purchase intention in sport marketing in China", Journal of Consumer Marketing, vol. 24, no. 6, pp. 358-365.

Malik, H. M., \& Qureshi, M. M., (2016), "The impact of celebrity endorsement on consumer buying behavior", Journal of Marketing and Consumer Research, vol. 26, pp. 112-127.

Mberia, M. M., (2014), "The effect of celebrity endorsement in advertisements", International Journal of Academic Research in Economics and Management Sciences, vol. 3, no. 5, pp. 178-188.

McCraken, G., (1989), "Who is celebrity endorser? Culture foundations of the endorsement process", Journal of Consumer Research, vol. 16, no. 3, pp. 310-321.

Makgosa, R., (2010), "The influence of vicarious role models on purchase intentions of Botswana teenagers", Young Consumers, vol.11, no. 4, pp. 307 - 319.

Mayer, R. C., Davis, J. H., \& Schoorman, F. D., (1995), “An integrative model of organizational trust", Academy of Management Review, vol. 20, no. 3, pp. 703-734.

Md. Said, N. P., \& Wan Napi, W. N., (2015), "Celebrity and non-celebrity endorsement effectiveness on consumers' attitude towards advertisement", International Academic Research Journal of Business and Technology, vol. 1, no. 2, pp. 51-57.

Mooij, M. D., \& Hofstede, G., (2011), "Cross-cultural consumer behavior: A review of research findings", Journal of International Consumer Marketing, vol. 23, pp. 181- 192.

Ohanian, R., (1990), "Construction and validation of a scale to measure celebrity endorsers' perceived expertise, trustworthiness, and attractiveness", Journal of Advertising, vol. 19, no. 3, pp. 39-52.

Pradhan, D., Duraipandian, I., \& Sethi, D., (2014), "Celebrity endorsement: How celebritybrand-user personality congruence affects brand attitude and purchase intention", Journal of Marketing Communications, pp. 1-18.

Pujawat, N., \& Noraini, W., (2015), "Celebrity and non-celebrity endorsement effectiveness on consumer attitude toward advertisement", International Academic Research Journal of Business and Technology, vol. 1, no. 2, pp. 51-57.

Rahman, S. A., Amran, A., Ahmad, N. H., \& Taghizadeh, S. K., (2015), "Enhancing the wellbeing of base of the pyramid entrepreneurs through business success: The role of private organizations", Journal of Social Indicators Research, vol. 127, no.1, pp. 195216.

Ranjbarian, B., Shekarchizade, Z., \& Momeni, Z., (2010), "Celebrity endorser influence on attitude toward advertisements and brands", European Journal of Sciences, vol. 13, no. 3, pp. 399-407.

Rashid, M. Z. A., Nallamuthu, J., \& Sidin, S. M., (2002), "Perceptions of advertising and celebrity endorsement in Malaysia", Asia Pacific Management Review, vol.7, no. 4, pp. 535-554.

Redenbach, A., (2005), "A multiple product endorser can be a credible source”, Cyber-Journal of Sport Marketing, vol.3, pp. 1-15.

Rhee, J. W., \& Lee, C., (2010), Cross-cultural interactions through mass media products: Cognitive and emotional impacts of Chinese people's consumption of Korean media products, Monash University ePress, Melbourne. 
Ringle C. M., Wende S., \& Will A., (2005), Smartpls 2.0 (M3 beta), Universität Hamburg, Hamburg.

Ryff, C. D., (1989), "Happiness is everything, or is it? Explorations on the meaning of psychological well-being", Journal of Personality and Social Psychology, vol. 57, no. 6, pp. 1069-1081.

Saeed, R., Zameer, H., Naseer, R., Haider, S., \& Naz, U., (2014), "Impact of celebrity and noncelebrity advertisement on consumer perception", Applied Sciences and Business Economics, vol. 1, no. 3, pp. 51-56.

Speck, P. S, David W. S., \& Craig T., (1988), "Celebrity endorsements: Scripts, schema and roles: Theoretical framework and preliminary tests, Advances in Consumer Research, vol. 15, pp. 69-76.

Silvera, D. H., \& Austad, B., (2003), "Factors predicting the effectiveness of celebrity endorsement advertisements", European Journal of Marketing, vol. 8, no. 11/12, pp. $1509-1526$.

Simon. H. A., (1953), "Notes on the observation and measurement of political power", The Journal of Politics, vol. 15, no. 4, pp. 500-516.

Subhadip, R., Gammoh, B. S., \& Koh, A. C., (2012), "Predicting the effectiveness of celebrity endorsements using the balance theory", Journal of Customer Behaviour, vol. 11, no. 1, pp. 33-52.

Tarde, G., (1969), The laws of imitation, University of Chicago Press, Chicago.

Thorson, E., (1990), "Consumer processing of advertising", Current Issues and Research in Advertising, vol. 12, pp. 197-230.

Till, B. D., Stanley, S. M., \& Priluck, R., (2008), "Classical conditioning and celebrity endorsers: An examination of belongingness and resistance to extinction", Psychology Market, vol. 25, pp. 179-196.

Ting, H., \& de Run, C., (2015), “Attitude towards advertising: A young generation cohort's perspective", Asian Journal of Business Research, vol. 5, no. 1, pp. 83-96.

Vu, H. T., \& Lee, T. T., (2013), "Soap operas as a matchmaker: A cultivation analysis of the effects of South Korean TV dramas on Vietnamese women's marital intentions", Journalism and Mass Communication Quarterly, vol. 90, no. 2, pp. 308-330.

Wang, J., Cheng, Y., \& Chu, Y., (2012), "Effect of celebrity endorsements on consumer purchase intentions: Advertising effect and advertising appeal as mediators, Journal of Human Factors and Ergonomics in Manufacturing and Service Industries, vol. 23, no. 5, pp. 357-367.

Yilmaz, C., Telci, E., Bodur, M., \& Iscioglu, T., (2011), "Source characteristics and advertising effectiveness", International Journal of Advertising, vol. 30, no. 5, pp. 889-914.

Zafar, Q-U-A., \& Rafique, M., (2015), "Impact of celebrity advertisement on customers' brand perception and purchase intention", Asian Journal of Business and Management Sciences, vol. 1, no. 11, pp. 53-67.

Zipporah, D. H., (2014), "The effect of celebrity endorsement in advertisements", International Journal of Academy Research in Economics and Management Sciences, vol. 3, no. 5, pp. $1-11$. 